\title{
EVALUATION OF SCROTAL LESIONS BY GRAY SCALE ULTRASONOGRAPHY AND COLOUR DOPPLER
}

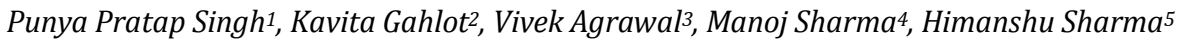 \\ ${ }^{1}$ Assistant Professor, Department of Radiodiagnosis, Bundelkhand Medical College, Sagar. \\ 2Medical Officer, Department of Emergency Medicine, Bundelkhand Medical College, Sagar. \\ 3 Senior Consultant \& Intervention Radiologist, Max Super Speciality Hospital, Saket, Delhi. \\ ${ }^{4}$ Senior Consultant, Max Super Speciality Hospital, Saket, Delhi. \\ ${ }_{5}^{5}$ Assistant Professor, Department of Pharmacology, Bundelkhand Medical College, Sagar.
}

\section{ABSTRACT}

\section{BACKGROUND}

Until the mid 1970's, scrotal examination was limited to palpation and transillumination. Miskin and Bain (1974) first reported the use of Ultrasonography to examine testes and scrotum. With advancement like colour Doppler, ability to assess testicular vascularity increased. Although other radiological investigations have roles in specific situations, present study was undertaken to evaluate the usefulness and accuracy of sonography and colour Doppler in scrotal abnormalities.

\section{METHODS}

The study was conducted in the Department of Radiodiagnosis, Max Super Speciality Hospital, Saket, New Delhi, between May 2012 and May 2013. Prospective study carried out in 100 patients after proper informed and written consent with inclusion criteria of 'All age patients with clinical suspicion of scrotal pathology' and exclusion criteria of 'History of operative or therapeutic procedures on the scrotum with exception of vasectomy.' These patients' scrotums were scanned in various plan on "Voluson 730 PRO" (GE Healthcare) system and LOGIC E-9 (GE Healthcare) using linear probe (As applicable) with comparison from asymptomatic side. Relevant other radiological and pathological investigations were done wherever indicated.

\section{RESULTS}

Majority of patients were between 21-40 years of age (62\%) with commonest presenting complaint was scrotal swelling in $73 \%$. Fluid collections were the commonest abnormality detected on sonography. Hydrocele was the most frequent fluid collection seen in 38 cases $(26.3 \%)$. In acute inflammation, hypoechogenicity of the testes was most common sonographic feature. In our study, ultrasound showed $99 \%$ accuracy to distinguish between Intratesticular and Extratesticular pathology.

\section{CONCLUSIONS}

High-resolution USG with colour Doppler can reliably define the morphological features and vascularity of scrotal lesions. USG is highly accurate in evaluating the consistency of scrotal mass and in localizing scrotal abnormality. Ultrasound evaluation of the scrotum must include colour Doppler imaging of testis and epididymis with comparison from the asymptomatic side.

\section{KEYWORDS}

High resolution ultrasonography, Colour Doppler, Hydrocele, Varicocele, Scrotal Wall Oedema.

HOW TO CITE THIS ARTICLE: Singh PP, Gahlot K, Agrawal V, et al. Evaluation of scrotal lesions by gray scale ultrasonography and colour Doppler. J. Evolution Med. Dent. Sci. 2016;5(57):3929-3940, DOI: 10.14260/jemds/2016/899

\section{INTRODUCTION}

Until 1970's examination of the scrotal contents was limited to palpation and transillumination. Miskin and Bain.[1] first reported the use of $B$ (Brightness)-mode Ultrasonography (USG) to examine testes and scrotum. USG have following advantages-High frequency transducers, haemodynamic information, low cost and rapidity in examination and freedom from radiation hazards.

\section{AIMS AND OBJECTIVES}

1. To evaluate spectrum of ultrasonographic findings in various scrotal pathologies.

Financial or Other, Competing Interest: None.

Submission 26-01-2016, Peer Review 02-03-2016,

Acceptance 07-03-2016, Published 16-07-2016.

Corresponding Author:

Dr. Punya Pratap Singh,

Flat -9, Type-IV Quarters,

Block-B, $2^{\text {nd }}$ Floor,

B.M.C. Campus, Sagar-470002,

Madhya Pradesh.

E-mail:drpunya@gmail.com

DOI: $10.14260 /$ jemds $/ 2016 / 899$
2. To evaluate value of colour Doppler in distinguishing and characterizing the blood flow patterns in scrotal pathologies.

3. To assess the role of high frequency real time ultrasonography to accurately distinguish between Testicular and Extratesticular scrotal masses.

\section{METHODS}

The study will be conducted in a tertiary referral teaching hospital; 100 patients were enrolled in the study after proper informed and written consent during the period of study with the following inclusion and exclusion criteria.

\section{Inclusion Criteria}

- Patients with all age groups.

- Patients with strong clinical suspicion of scrotal pathology referred for scrotal duplex sonography.

\section{Exclusion Criteria}

- Patients with previous history of operative or therapeutic procedures on the scrotum with exception of vasectomy. 


\section{METHOD OF EXAMINATION}

\section{Sonography and Colour Doppler Technique}

The examination was performed in a setting that affords adequate comfort and privacy to patient. The patient was asked to lie supine comfortably with the legs slightly separated. The scrotum was scanned with the spermatic cord and groin region. Varicocele examination was performed in supine posture with Valsalva manoeuvre and in erect posture to confirm it. Thereafter, CD (Colour Doppler) and pulsed Doppler were performed to depict flow in the vessels. Comparison was always made with the asymptomatic contralateral side and findings are analysed. In patients with suspicion of testicular tumours, other regions were scanned to look for the presence of secondaries. In case of varicocele, especially the left side, the kidneys were scanned to rule out renal mass.

Chest Radiograph (Postero-Anterior View), Computed Tomography and Laboratory Investigations

It was taken in those cases which were suspected to have testicular tumour to detect retroperitoneal lymph nodes and metastases and in suspected tubercular epididymis with relevant histopathological investigations.

\section{RESULTS}

Commonest age group is $21-40$ years, which is $62 \%$ of patients.

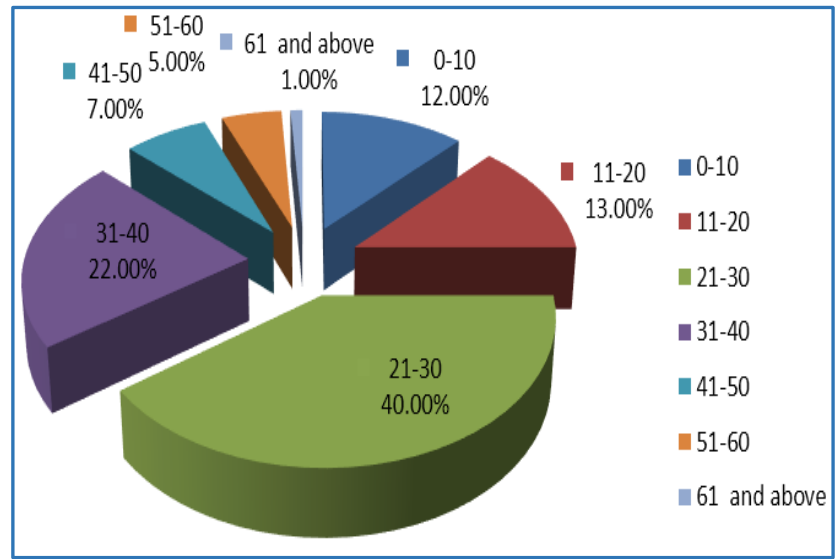

Fig. 1: Age Distribution of Cases

Commonest presentation was scrotal swelling in $73 \%$ cases.

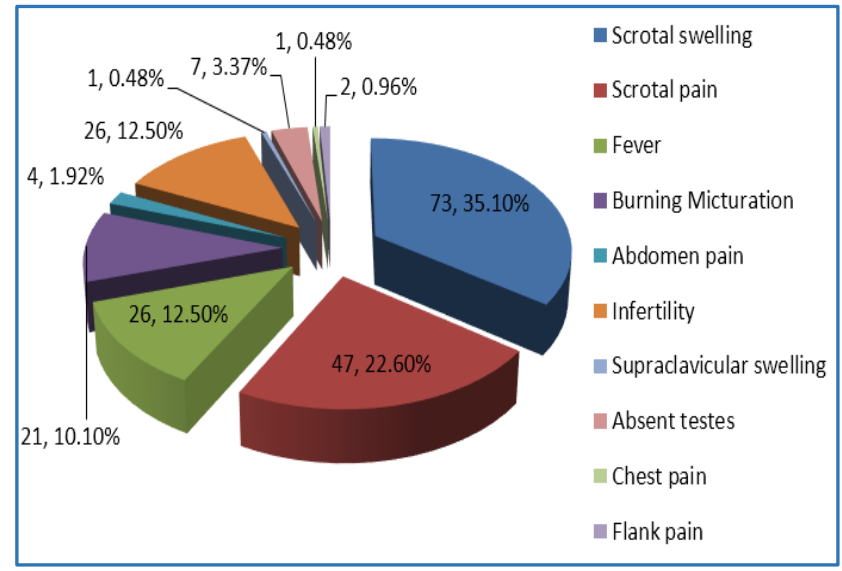

Fig. 2: Clinical Symptomatology

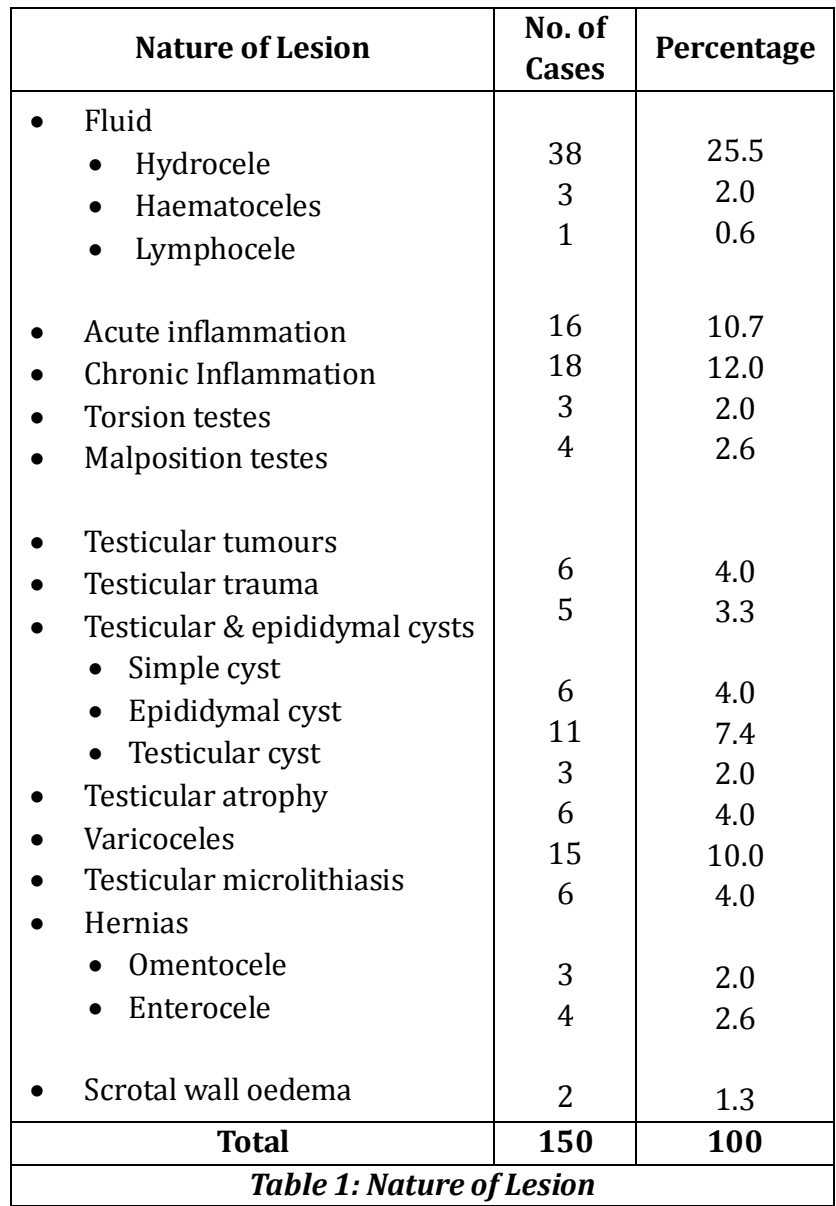

Fluid collections were the commonest abnormality with hydrocele was most common type [Table - 1].

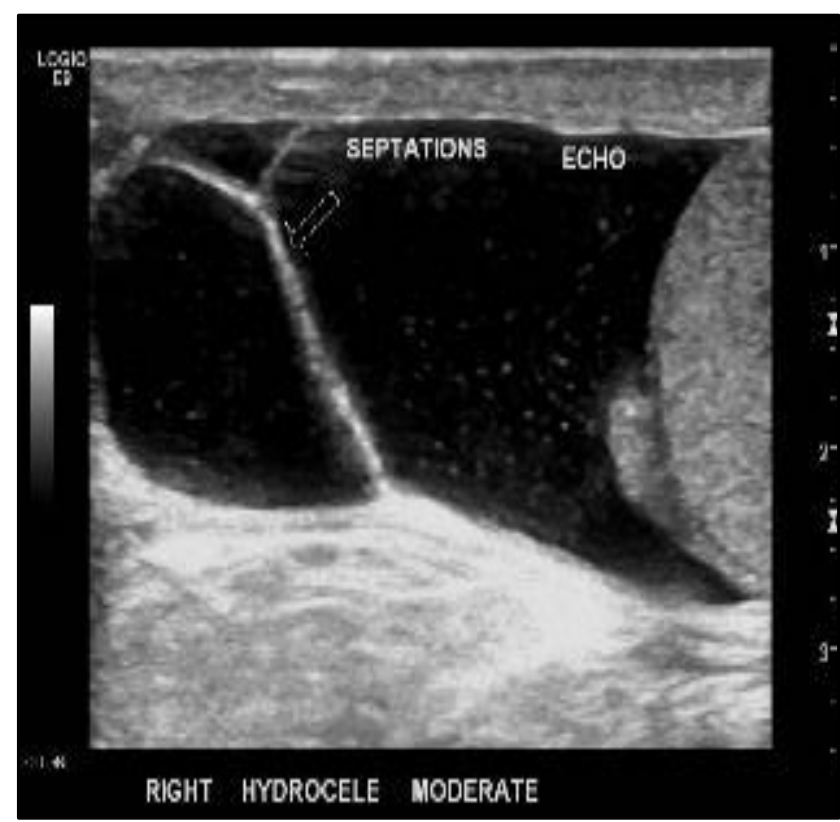

Fig. 3: Right Moderate Hydrocele with Internal Echoes and Internal Septations

The fluid was anechoic in $71.1 \%$ and without any septation in $78.9 \%$ cases. Associated abnormality was noted in $84.2 \%$ cases of hydrocele. On CD study, the vascularity is normal. 


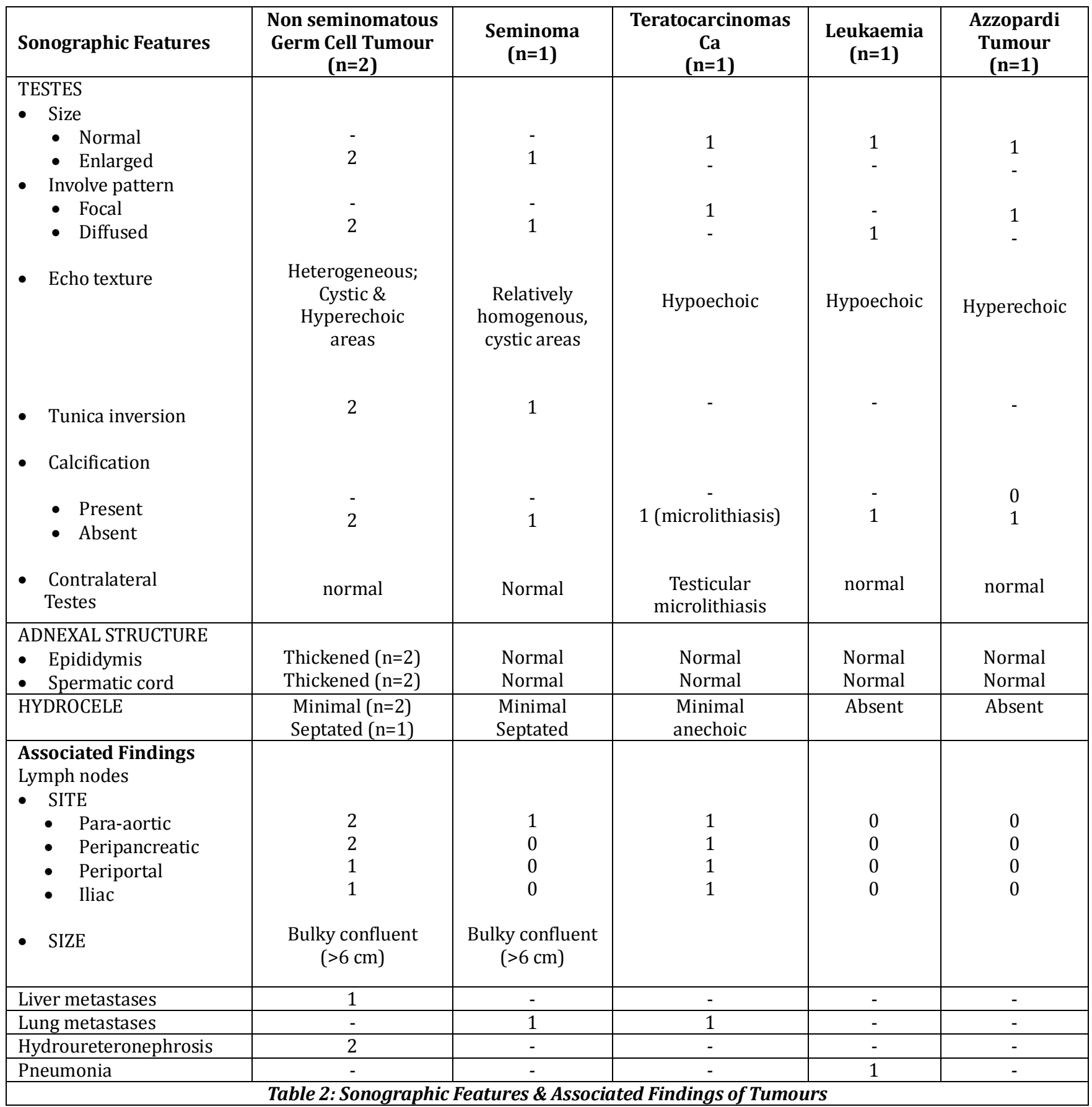

Six cases of testicular tumours were encountered in the study. Tumour lesions are comparatively hypoechoic in $83 \%$ of cases [Table - 2].

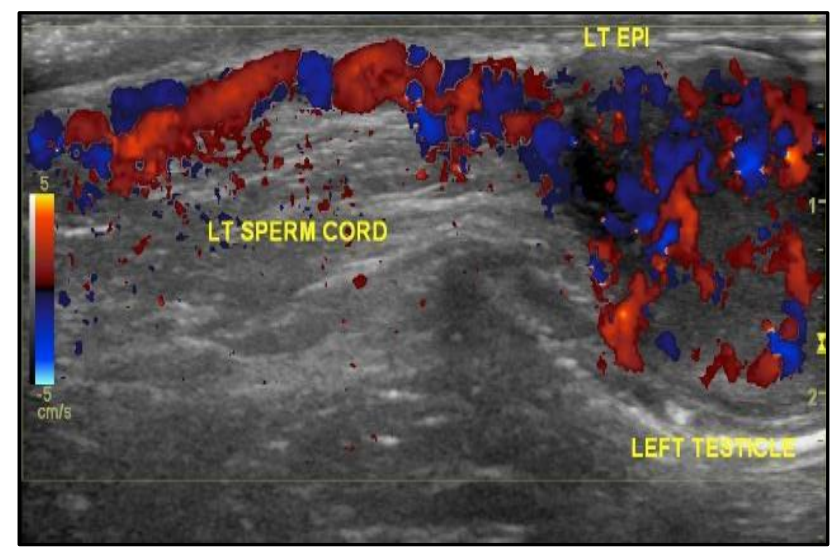

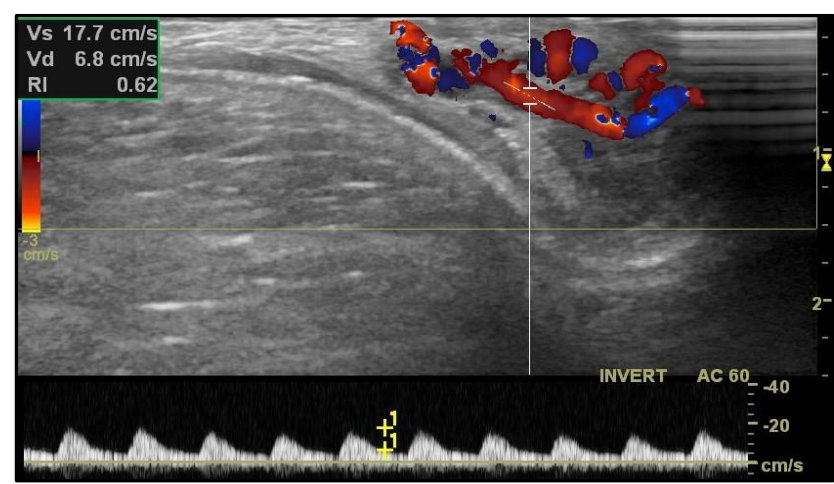

Fig. 4: Lt. Testicular Tumour (A) - Left Testis enlarged in size with markedly increased diffuse vascularity. (B) Showing increased vascularity of Lt. epididymis with increased peak systolic velocity $(>15 \mathrm{~cm} / \mathrm{sec})$ and reduced resistivity index (<7.0) noted in left testicular artery. 

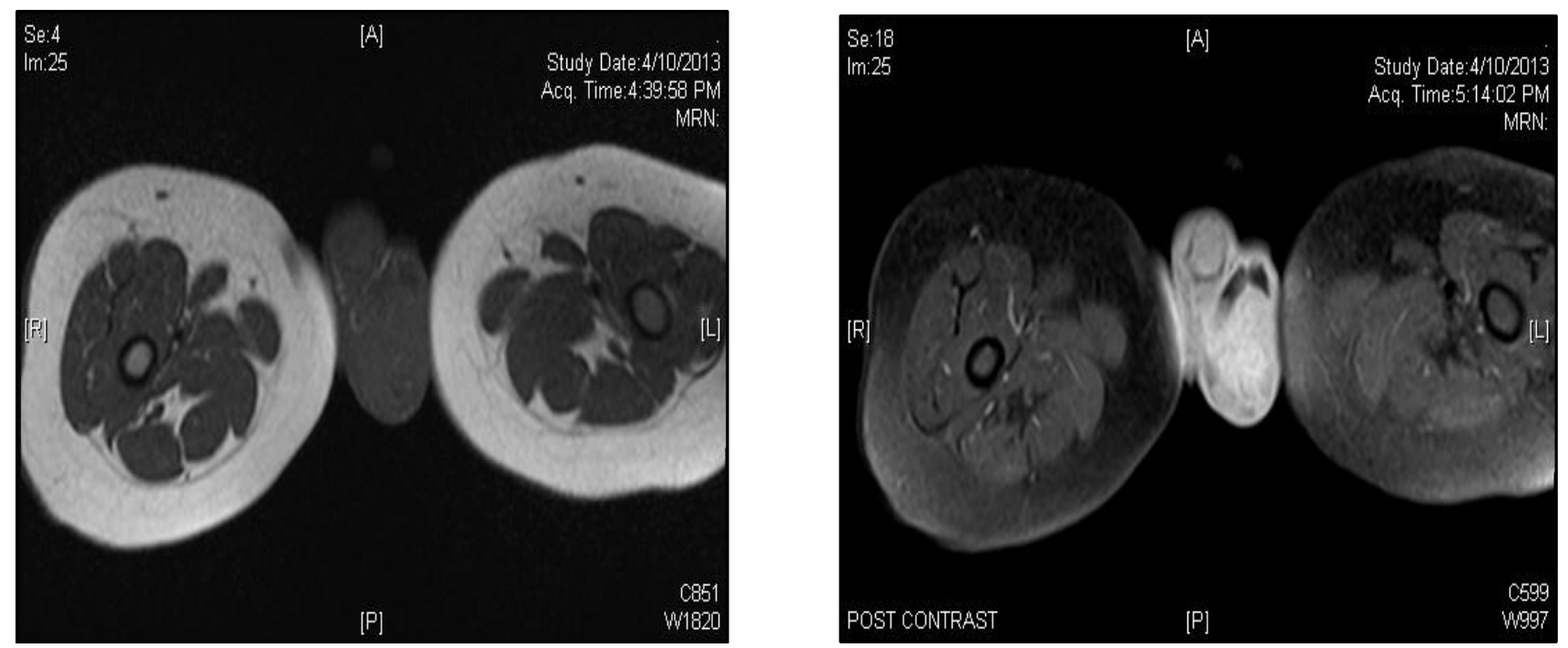

Fig. 4: Left Testicular Tumour (C\&D) T1WI Transverse Image showing Increased Size of Left Testis with Isointense Signals Post contrast T1 W Fat Suppressed Image was showing Marked Homogeneous Contrast Enhancement
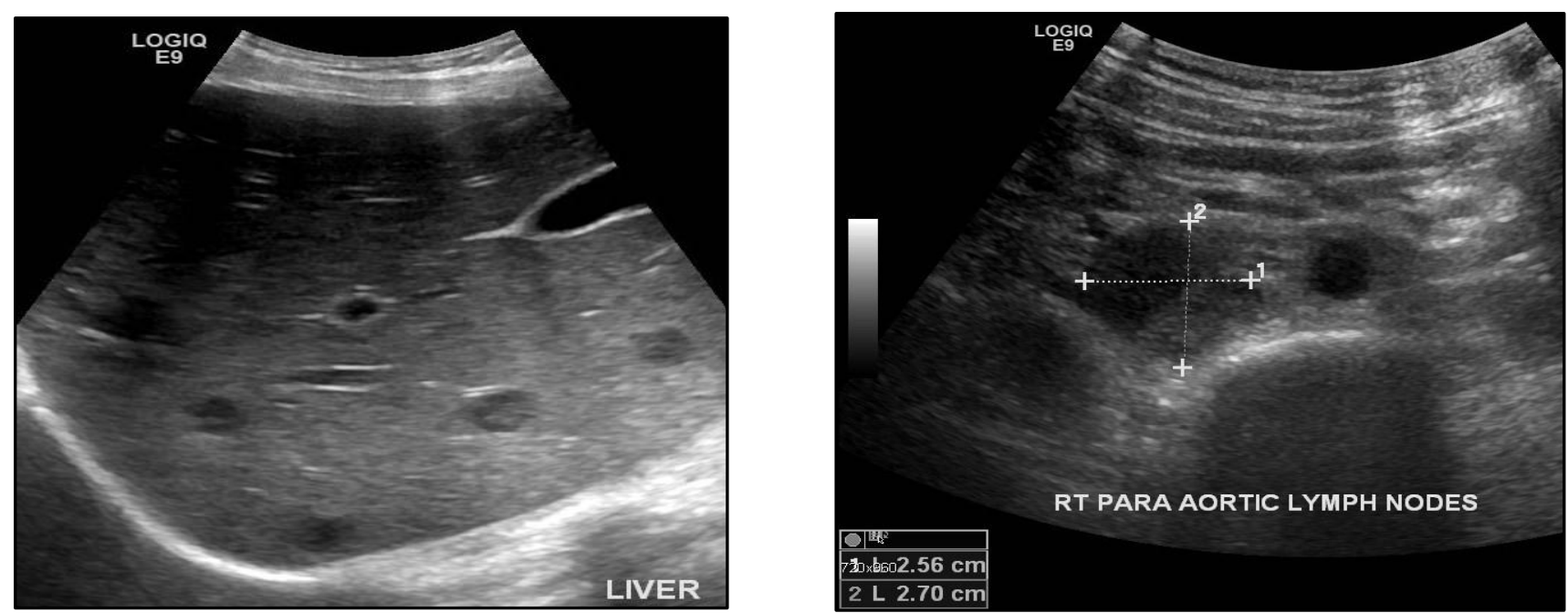

Fig. 4: (E\&F): Left Testicular Tumour-Multiple Rounded Hypoechoic Lesions seen involving Liver Parenchyma (Liver Metastasis). Enlarged well-defined Hypoechoic RT Para-aortic Lymph Node also noted
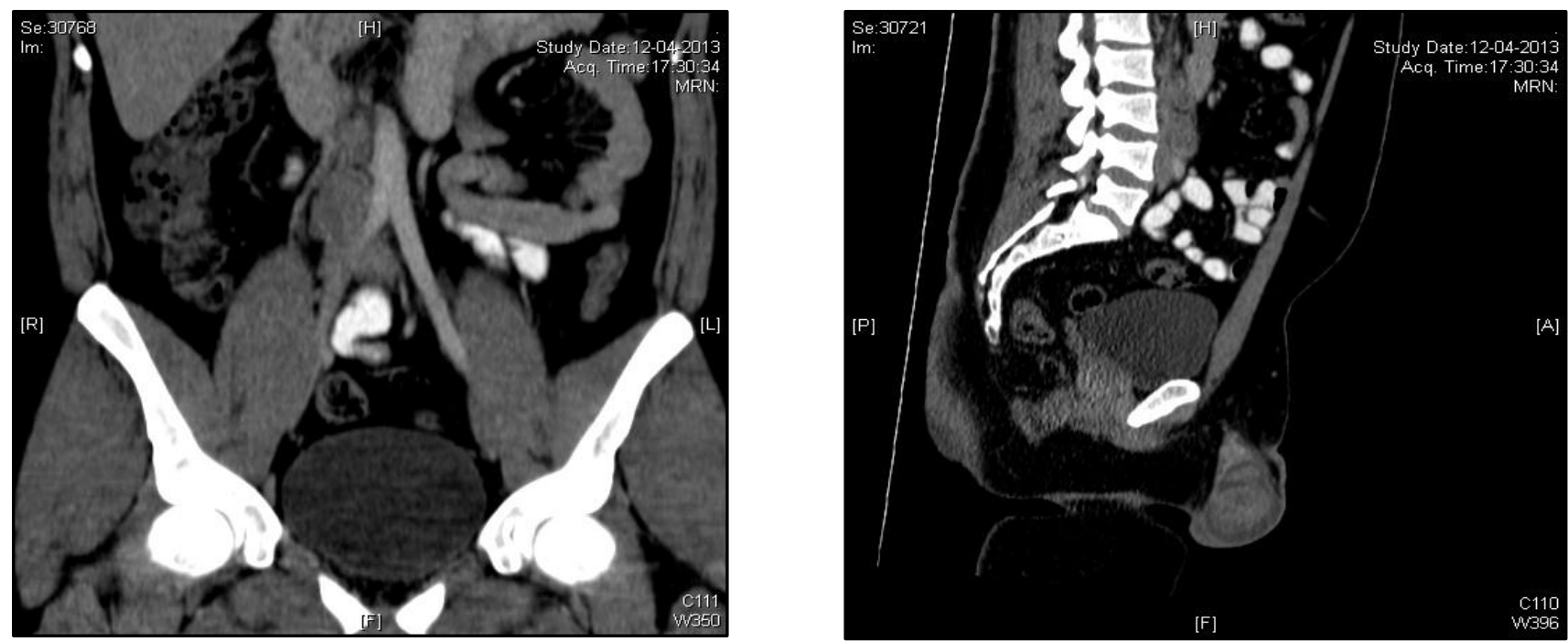

Fig. 4 (G): Left Nonseminomatous Germ Cell Tumour - Computed Tomography Reformate Pictures showing Para-aortic Lymph Nodes 


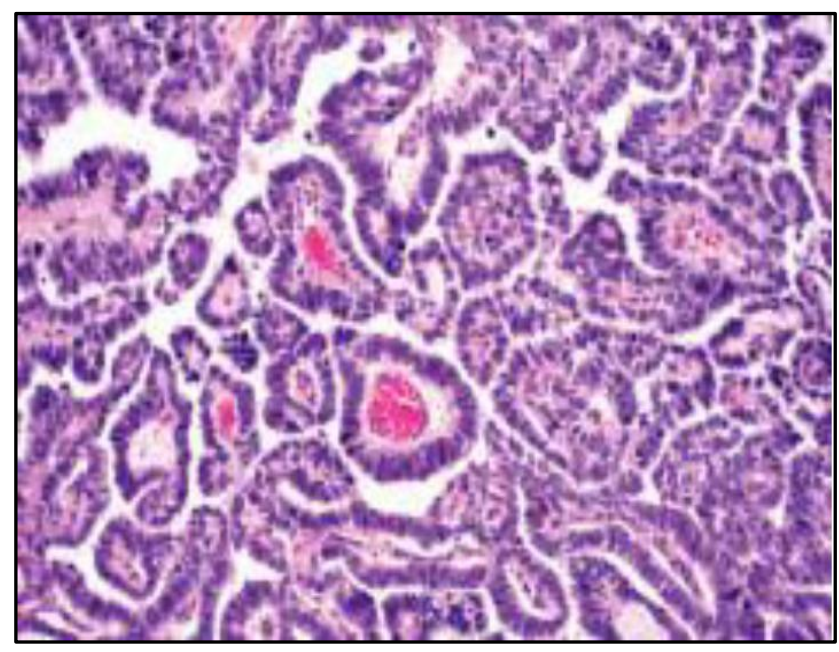

Fig. 4 (H): Lt. Testicular Tumour turned out to be Yolk Sac Tumour on Histopathological Examination

(Micrograph was showing Yolk Sac Tumour with SchillerDuval Bodies, H\&E Stain, 50x)

\begin{tabular}{|c|c|c|c|c|c|}
\hline Features & $\begin{array}{c}\text { Nonseminomatous } \\
\text { Germ Cell } \\
\text { Tumour } \\
\end{array}$ & Seminoma & Teratocarcinoma & Leukaemia & $\begin{array}{r}\text { Azzopardi } \\
\text { Tumours }\end{array}$ \\
\hline $\begin{array}{l}\text { SIZE OF LESION } \\
\text { - Less than } 1.6 \mathrm{~cm} \\
\text { - More than } 1.6 \mathrm{~cm}\end{array}$ & - & - & $\begin{array}{l}1 \\
-\end{array}$ & - & $\begin{array}{l}1 \\
-\end{array}$ \\
\hline Colour Doppler & $\begin{array}{c}\text { Normal-1 } \\
\text { Increased-1 }\end{array}$ & Increased & Normal & Increased & Decreased \\
\hline PATTERN OF FLOW & $\begin{array}{c}\text { Unevenly } \\
\text { distributed vessels }\end{array}$ & $\begin{array}{c}\text { Unevenly } \\
\text { distributed vessels }\end{array}$ & & $\begin{array}{c}\text { Evenly distributed } \\
\text { vessels }\end{array}$ & \\
\hline $\begin{array}{l}\text { SPECTRAL ANALYSIS } \\
\text { - Peak Systolic } \\
\text { Velocity }>19.8 \mathrm{~cm} / \mathrm{sec} \\
\text { - Resistivity Index }<0.7\end{array}$ & $\begin{array}{l}2 \\
2\end{array}$ & $\begin{array}{l}1 \\
1\end{array}$ & $\begin{array}{l}- \\
-\end{array}$ & - & $\begin{array}{l}- \\
-\end{array}$ \\
\hline
\end{tabular}

In 16 cases of acute inflammation, $50 \%$ were young and sexually active age group; $30.5 \%$ was showing hypoechogenicity of the testes. Epididymis was the commonest anatomical structure involved. CD could demonstrate increased flow in 50\% testes and $80 \%$ epididymis.

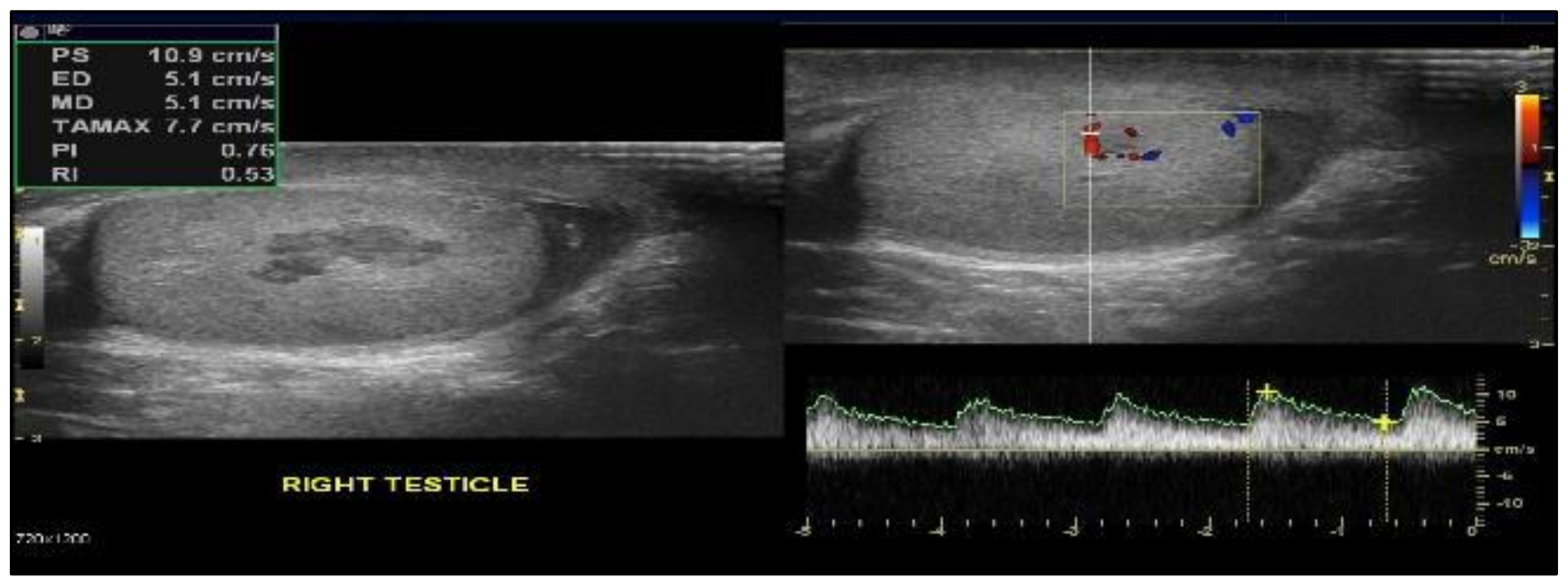

Fig. 5: Focal Orchitis seen as focal altered Hypoechoic Intratesticular Lesion showing increase Vascularity. In Colour Doppler Study Right Testis showing Increased Diastolic Flow and Reduced Resistivity Index (<0.7). However, Peak Systolic Velocity was within Upper Limits of Normal ( $<15 \mathrm{~cm} / \mathrm{sec})$. 


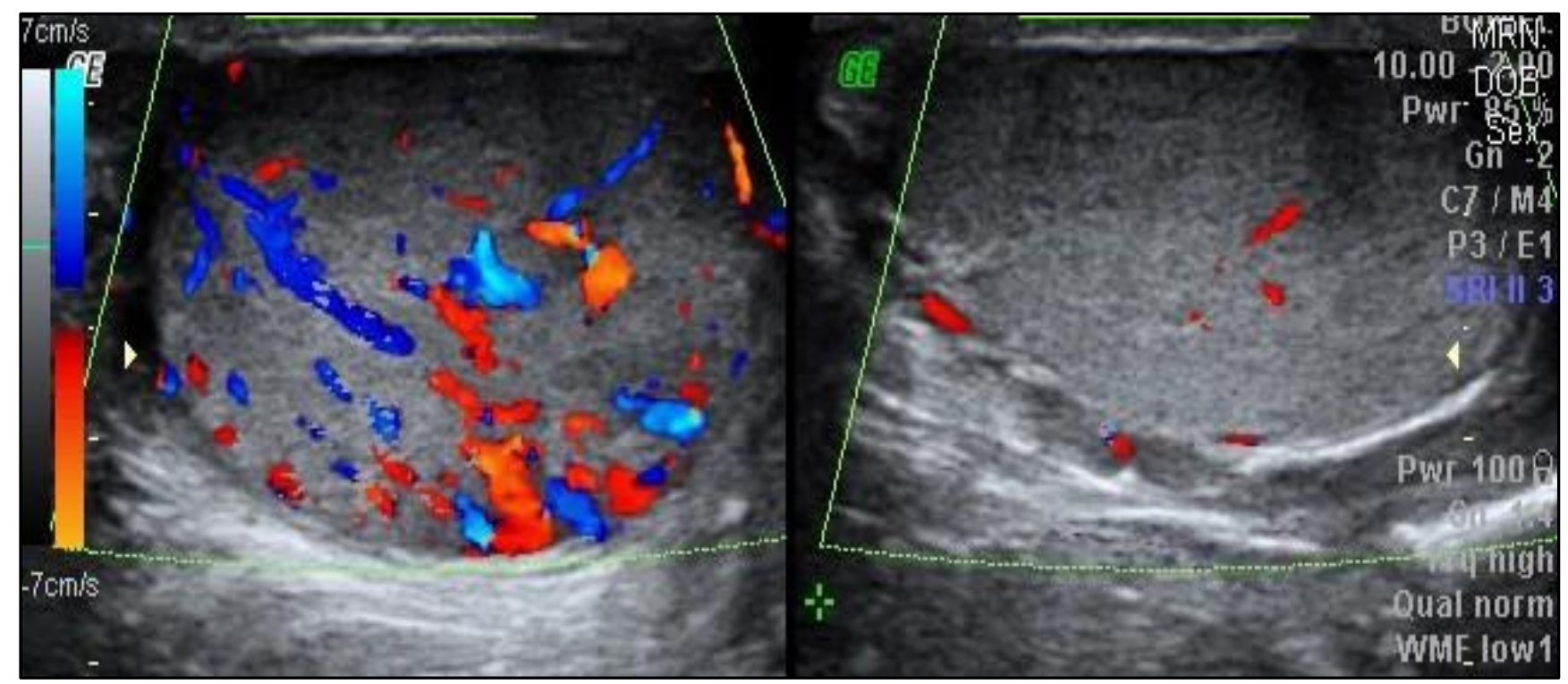

Fig. 6 (A): Right Testis has Increased in Size and More Hypoechoic in Echotexture as compared to Left Testis. Right Testis showing more Vascularity as compared to Left Testis

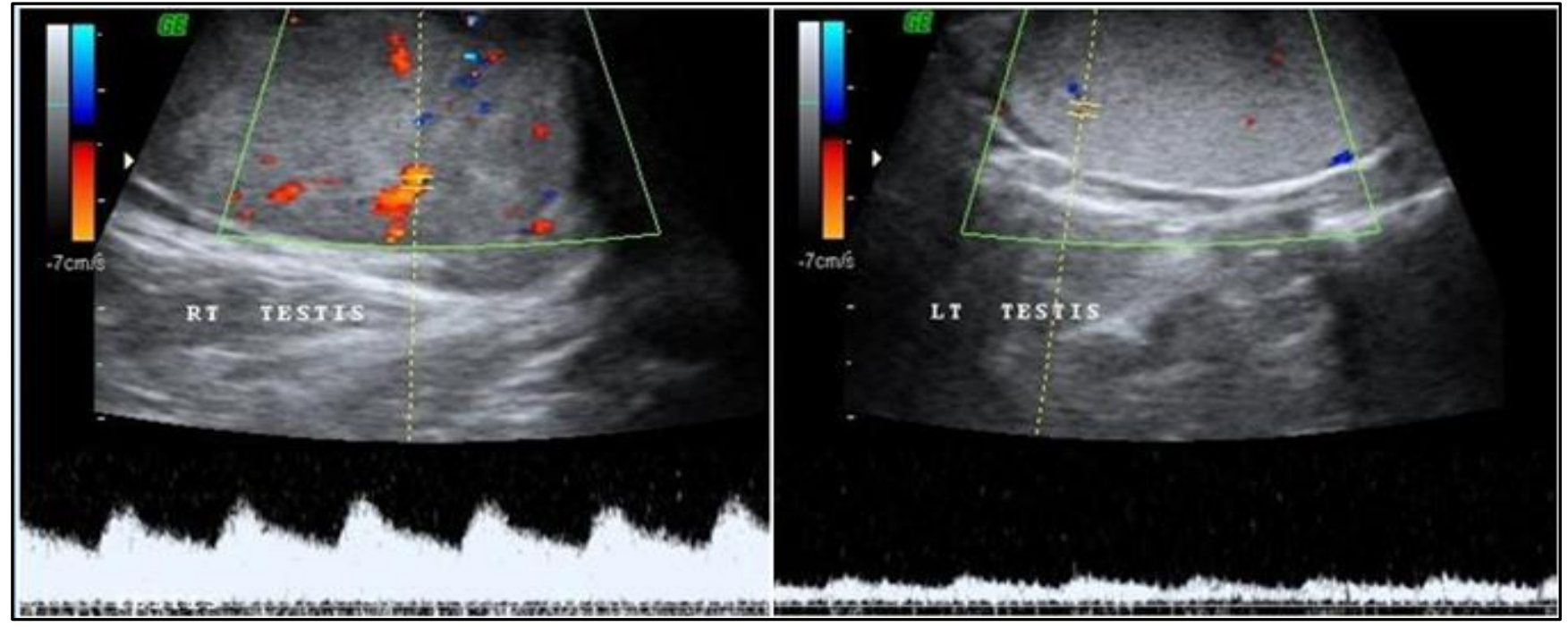

Fig. 6 (B\&C): Right Testis showing Increased Vascularity, More Peak Systolic Velocity and Increased Diastolic Flow

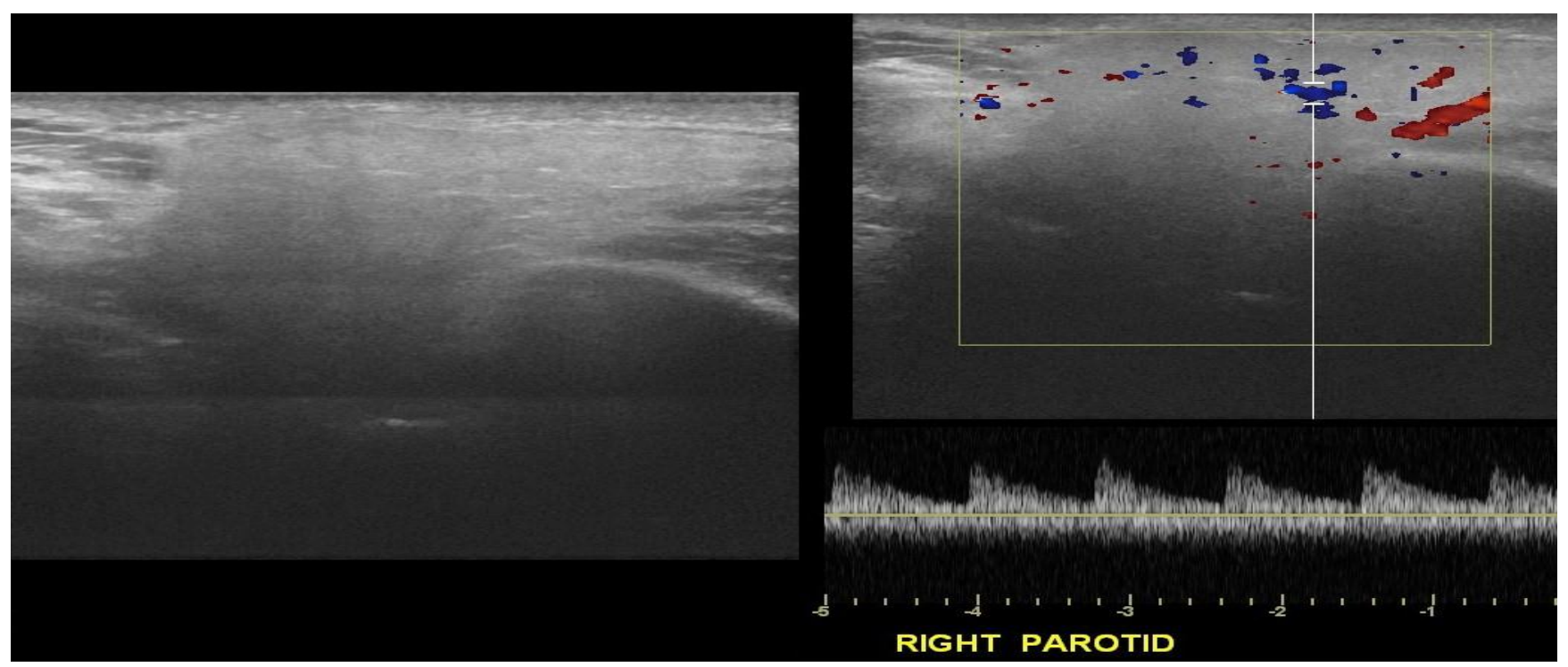

Fig. 6 (D): Right Parotid Gland showing Hypoechoic Echotexture with Increased Vascularity. These Findings are consistent with Acute Parotitis 


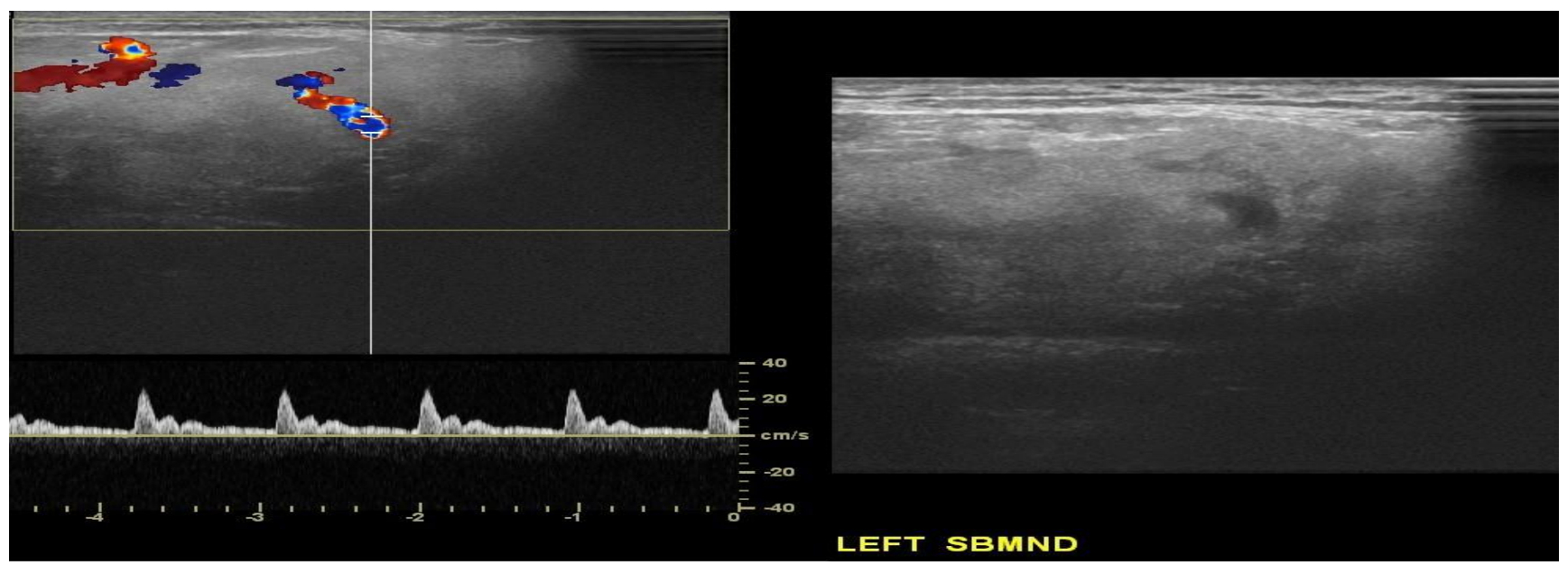

Fig. 6 (E\&F): Right Submandibular Gland was showing Heterogeneous Echotexture with Increased Vascularity suggestive of Acute Inflammatory Changes

$87 \%$ cases of orchitis demonstrate a PSV of more than $15 \mathrm{~cm} / \mathrm{sec}$ and $75 \%$ cases demonstrate RI (Resistivity Index) less than 0.7. Chronic inflammation of scrotal structures, in majority of cases involvement of epididymis noted and showing hypoechoic echotexture. One testes (5.5\%) normal on gray scale showed increased vascularity on CD study and was considered abnormal.

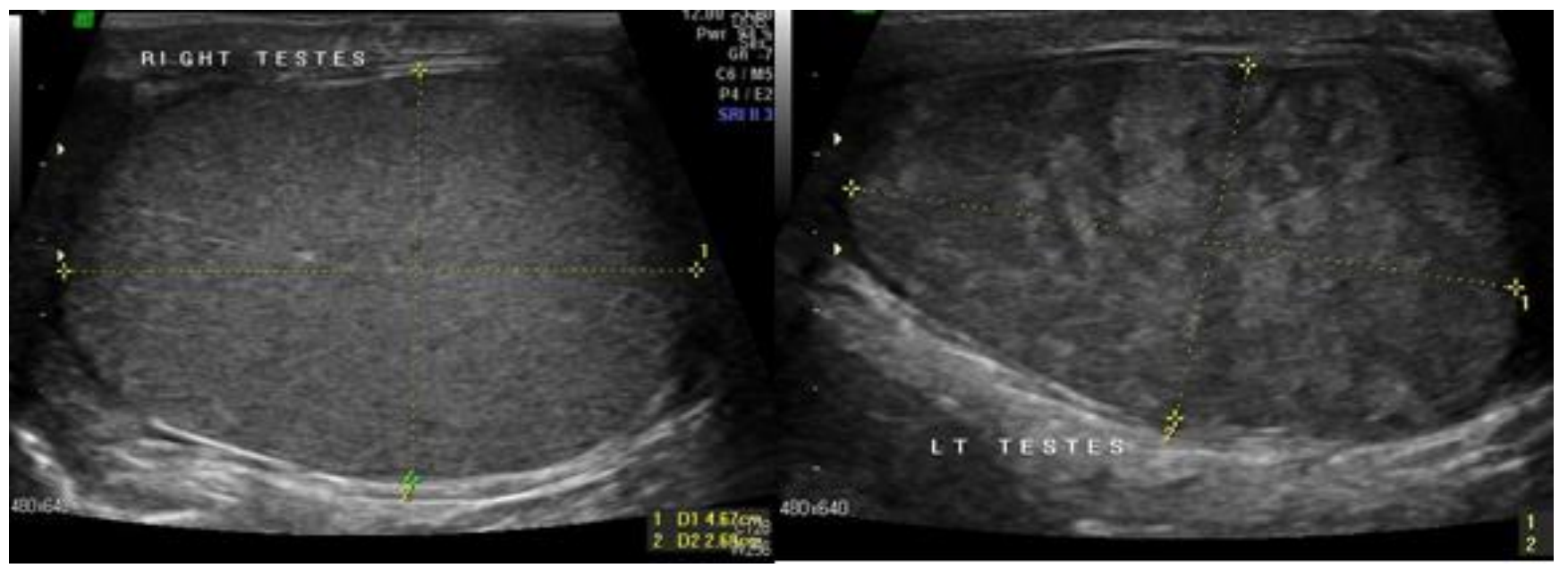

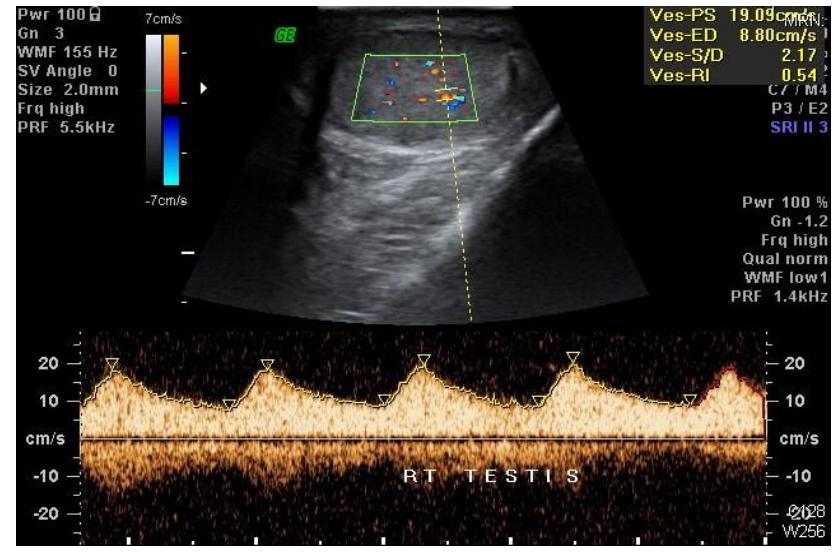

Fig. 7: Left Chronic Orchitis - (A) Left Testis was increased in size with altered Heterogeneous Echotexture. (B) On colour Doppler study, Left Testis showing increased Vascularity (Peak Systolic Velocity $>15 \mathrm{~cm} / \mathrm{sec}$ ) and increased Diastolic Flow (Resistivity Index <7.0)

One case $(5.5 \%)$ of epididymitis was also noted on $C D$, which was not apparent on gray scale sonography. Cases of chronic testicular torsion, commonest pattern was enlarged testes (66.6\%) with heterogeneous echopattern (66.6\%). With
CD blood flow in symptomatic testes was absent in all three cases $(100 \%)$. In four cases of testicular trauma, hyperechoic echopattern is noted in 50\% cases. Discrete fracture identified in $25 \%$ cases with haematocele in $75 \%$ cases.

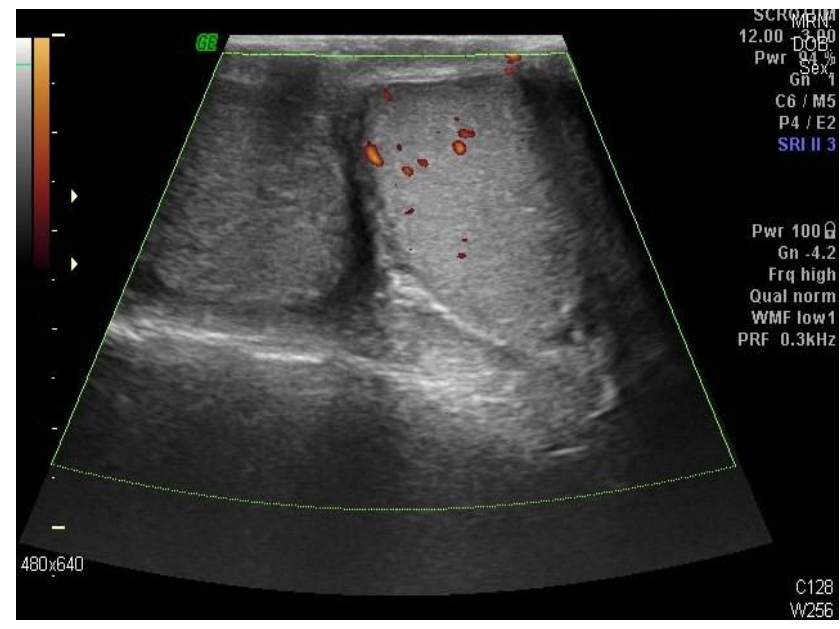

Fig. 8: (A) Right Testicular Torsion - Hypoechoic Echotexture of Right Testis without Intratesticular Vascularity 

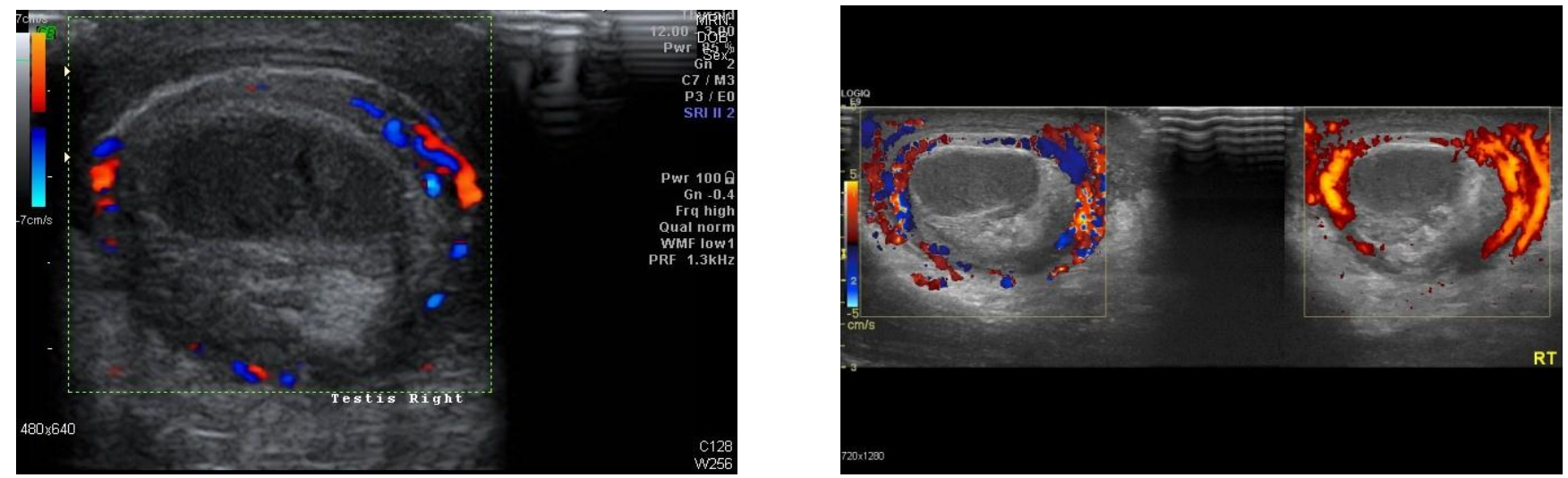

Fig. 8 (B\&C): Right Testicular Torsion - Hypoechoic Echotexture of Right Testis without Intratesticular Vascularity. Extratesticular Vessels were showing Vascular Flow

Testicular atrophy cases, most common heterogeneous pattern noted in $66.6 \%$ cases and reduced flow signals in $100 \%$ cases.

Varicocele was seen on left side in $86.7 \%$ cases and $13.3 \%$ on right side. All cases demonstrated accentuation on Valsalva manoeuvre with $73.3 \%$ cases show reflux.
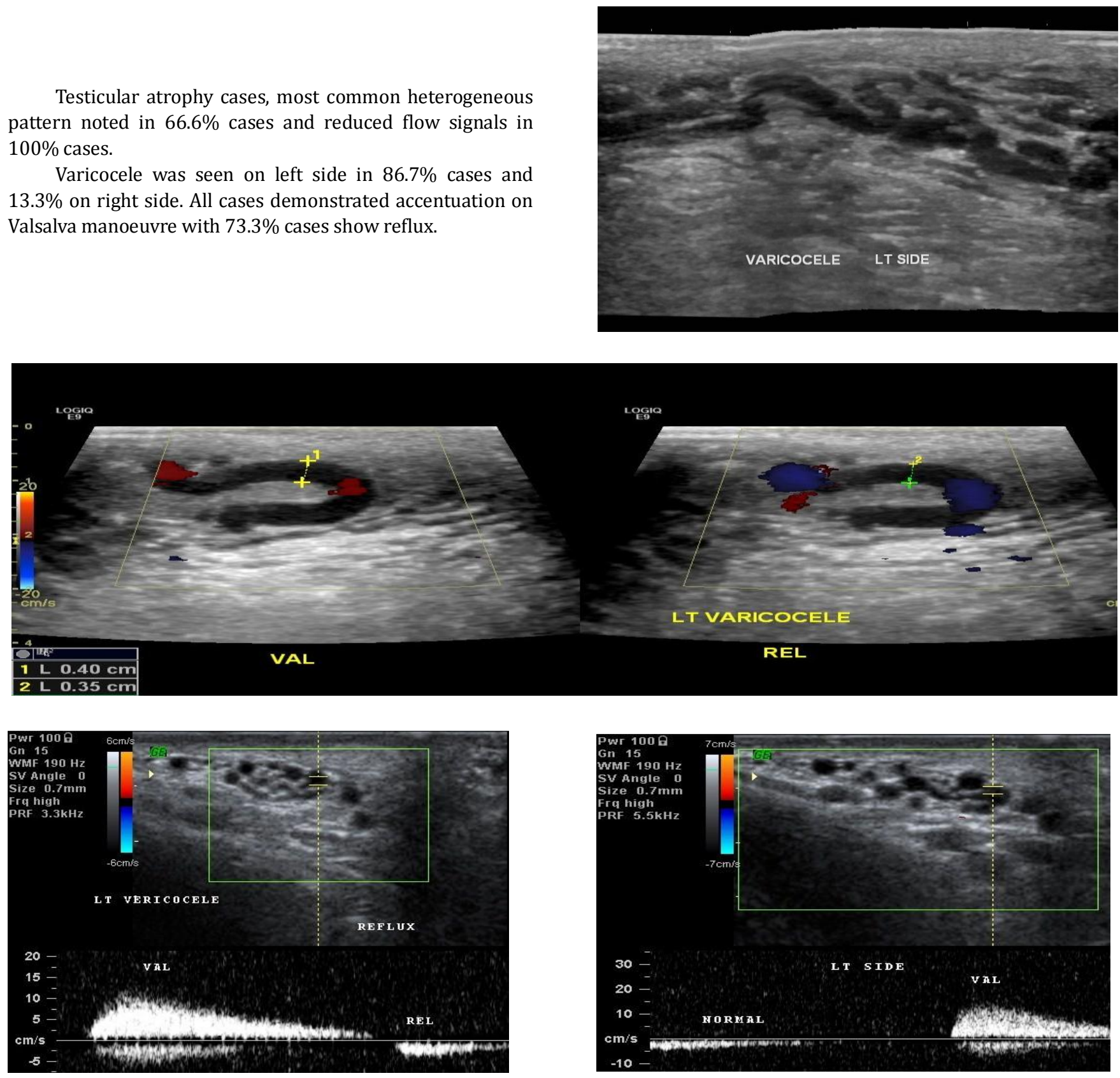

Fig. 9: Right Varicocele (A) Multiple Dilated Anechoic Serpiginous Structure seen in Left Scrotal Sac. (B) On colour Doppler study, Serpiginous Structure was showing Reflux as change in Colour signal (Red to Blue) and Prominence as Increased Luminal Diameter on Valsalva Manoeuvre. (C) On Spectral Analysis, these venous channels showing reversal of Flow Signify Reflux 


\begin{tabular}{|c|c|c|}
\hline Features & $\begin{array}{l}\text { No. of } \\
\text { Cases }\end{array}$ & Percentage \\
\hline $\begin{array}{l}\text { Max size of spermatic veins } \\
\text { - } 2-3 \mathrm{~mm} \\
\text { - } 3-4 \mathrm{~mm} \\
\text { - }>4 \mathrm{~mm}\end{array}$ & $\begin{array}{l}4 \\
5 \\
6\end{array}$ & $\begin{array}{c}26.7 \\
33.3 \\
40\end{array}$ \\
\hline $\begin{array}{l}\text { Tortuosity of vessels } \\
\text { - Present } \\
\text { - Absent }\end{array}$ & $\begin{array}{c}12 \\
3\end{array}$ & $\begin{array}{l}80 \\
20 \\
\end{array}$ \\
\hline $\begin{array}{l}\text { Accentuation on } \\
\text { - Valsalva manoeuvre } \\
\text { - Erect posture }\end{array}$ & $\begin{array}{l}15 \\
15\end{array}$ & $\begin{array}{l}100 \\
100\end{array}$ \\
\hline $\begin{array}{l}\text { Colour Doppler features } \\
\text { - Increase } \\
\text { - Normal } \\
\text { - Decrease }\end{array}$ & $\begin{array}{c}13 \\
0 \\
2 \\
\end{array}$ & $\begin{array}{c}86.7 \\
0 \\
13.3 \\
\end{array}$ \\
\hline $\begin{array}{l}\text { Spectral analysis } \\
\text { - Maximum flow velocity } \\
\text { - }>6 \mathrm{~cm} / \mathrm{sec} \\
\text { - } 4-6 \mathrm{~cm} / \mathrm{sec} \\
\text { - } 2-4 \mathrm{~cm} / \mathrm{sec} \\
\text { - }<2 \mathrm{~cm} / \mathrm{sec} \\
\text { - Reflux grade } \\
\text { - Grade } 1 \\
\text { - Grade } 2 \\
\text { - Grade } 3\end{array}$ & $\begin{array}{c}2 \\
6 \\
5 \\
2 \\
\\
2 \\
3 \\
10\end{array}$ & $\begin{array}{c}13.3 \\
40 \\
33.4 \\
13.3 \\
\\
13.3 \\
20 \\
66.7\end{array}$ \\
\hline
\end{tabular}

Seven percent of cases showed spermatocele as compared to $11 \%$ of epididymal cysts were identified and confirmed on aspiration. Omentocele was seen in 3\% cases, while enterocele in four cases. Thus hernial incidence of $7 \%$ was noted.

In our study, testicular microlithiasis was encountered in $6 \%$ cases. Four cases had bilateral testicular microlithiasis with associated teratocarcinoma on one side was found in one case.

The incidence of cryptorchidism was $4 \%$ in our series. Most common position was in inguinal canal and smaller than their contralateral counterpart in $50 \%$ cases. On sonography, $75 \%$ were homogeneous and hypoechoic in echotexture with torsion noted in one case. On sonography two testes (50\%) were homogeneous and hypoechoic in echotexture.

\begin{tabular}{|l|c|c|}
\hline \multicolumn{1}{|c|}{ Features } & No. of Cases & Percentage \\
\hline POSITION OF TESTES & & \\
- Inguinal & 3 & 75 \\
- Deep inguinal ring & 1 & 25 \\
- Other & 0 & 0 \\
\hline SIZE & & \\
- Increased & 1 & 25 \\
- Normal & 2 & 50 \\
- Decreased & 1 & 25 \\
\hline ECHOPATTERN & & \\
- Normal & 1 & 25 \\
- Hypoechoic & 2 & 50 \\
- Hyperechoic & 0 & 0 \\
- Heteroechoic & 1 & 25 \\
\hline
\end{tabular}

\begin{tabular}{|l|c|c|}
\hline ASSOCIATED FEATURES & & \\
- Torsion & 1 & 25 \\
- Inguinal hernia & 1 & 25 \\
- Hydrocele & 2 & 50 \\
\hline \multicolumn{2}{|c|}{ Table 5: Undescended Testes Features } \\
\hline
\end{tabular}

Two cases depicted a thickened scrotal wall with normal testes. On CD increased vascularity were identified in the scrotal wall, which had high resistance blood flow with RI values more then $7,0.81$ and 0.78 respectively.

Omentocele was $3 \%$ cases, while enterocele in $4 \%$ cases. Thus, an incidence of $7 \%$ was noted. In our study, sonography revealed a highly echogenic mass separated from the testes in omental hernia and anechoic mass in inguinoscrotal region of in cases of enterocele. On $\mathrm{CD}$, vascular signals were demonstrated within the bowel wall and within the omentum.
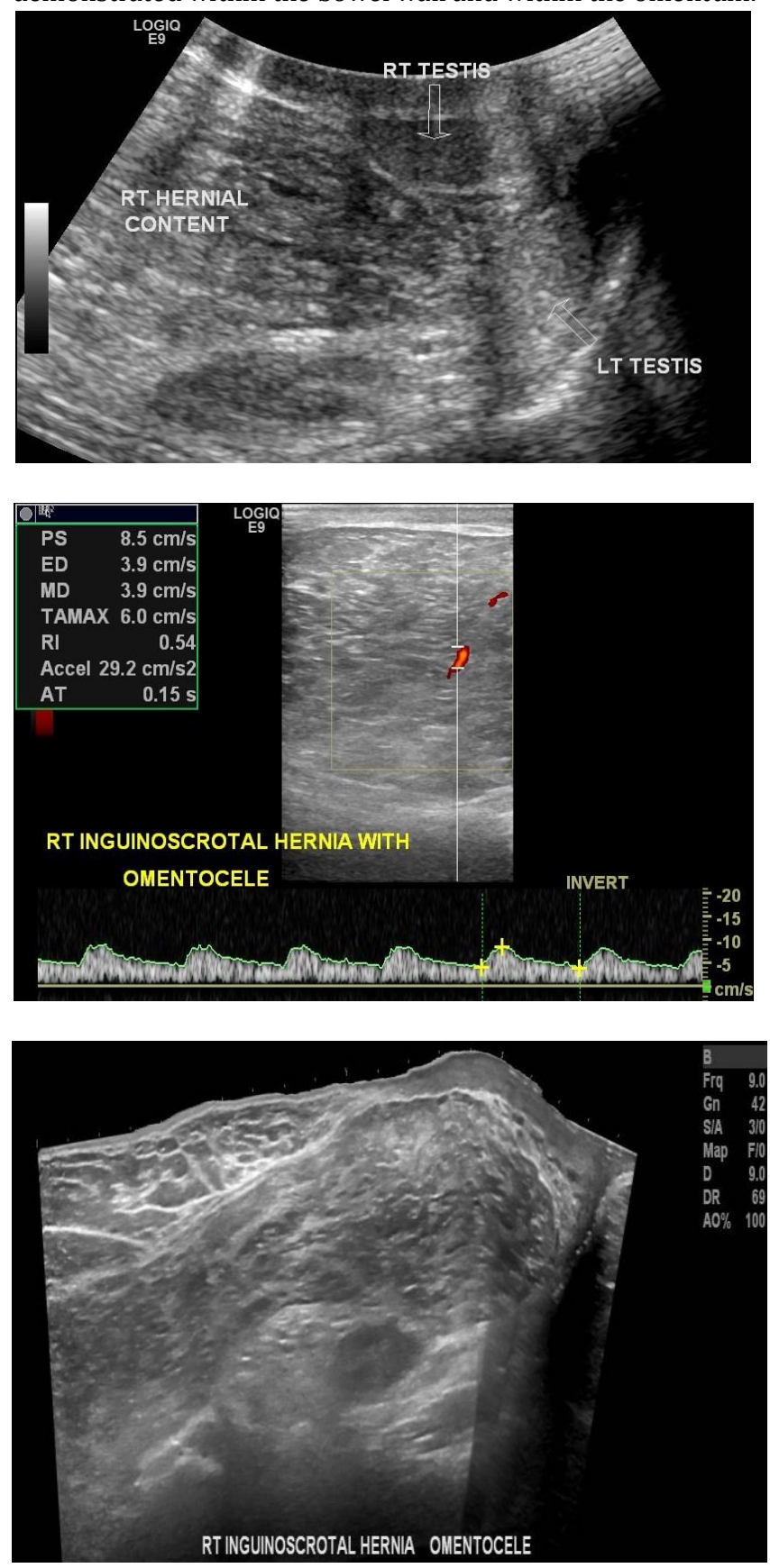

Fig. 10 (A,B\&C): Right Inguinal Hernia with Omentum as Hernial Content 
One postoperative case of herniorrhaphy was studied, which had multiseptated collections in the spermatic cord. Another patient had thickened spermatic cord with no traceable vascular signals in the cord or ipsilateral testes. The testes had atrophied in this case.

Three malignant cysts noted with features of multilocularity, shaggy, thick and irregular wall, echogenic content and hypervascularity.

Majority of pathologies was showing extratesticular involvement $(62 \%$ cases $)$. Intratesticular and both (Intratesticular and extratesticular) involvement noted in $10 \%$ and $27 \%$ cases respectively. In one case, we cannot identify testis (A case of traumatic haematocele). So, in our study high frequency ultrasound showed $99 \%$ accuracy to distinguish between Intratesticular and Extratesticular pathology.

\section{DISCUSSION}

100 patients with scrotal lesions were included in this study. Predominant group in the study was 21 to 30 years comprising of $42 \%$ cases. Commonest presenting complaint was that of scrotal swelling in $73 \%$ followed by $34.4 \%$ scrotal pain.

\section{Fluid Collections}

Fluid collections were the commonest abnormality with hydrocele as most frequent fluid collection, same reported by Langer et al.[2] Thus, accuracy of $100 \%$ was achieved in diagnosing Hydrocele same as reported by Gutman et al.[3]

All cases of haematocele showed fluid with internal echoes and septations considered diagnostic of haematocele also by Stewart et al.[4] A case of lymphocele with lymphatic collection in inguinoscrotal region and upper thigh. Chung et al. ${ }^{[5]}$ have described these features in case of lymphocele.

\section{Testicular Tumours}

In the present study, all cases of testicular tumours were encountered and diagnosed in all cases with nearly same accuracy reported by Fowler et al.[6]

The sonographic characteristic of testicular tumours was the heterogeneous appearance of the testes. Tumour lesions appeared less echogenic than normal testes in $83 \%$ of cases, also reported by Arger et al.[7]

The seminoma was hypoechoic, homogeneous and had sharply circumscribed margins, while Nonseminomatous Germ Cell Tumours (NSGCT) were characterized by heterogeneous echotexture, irregular margins and cystic spaces. Similar observations were made by Nachtscheim et al.[8]

A case of Azzopardi tumour was noted. Grantham et al.[9] also reported hyperechoic foci in six out of seven regressed germ cell tumours of the testes.

Testicular microlithiasis was noted in one case (16.6\%) of testicular tumour. Berger et al.[10] reported microlithiasis to be present in $35 \%$ of their patients with testicular tumours.

The distribution of blood vessels within the tumour was random and disorganized in hypervascular tumours. These findings were similar to those observed by Horstman et al.[11]

Enlarged para-aortic lymph nodes were the most common site of metastases detected in $66.6 \%$ cases of tumours. This feature was also observed by Mostofi FK et al.[12]

\section{Acute Inflammation}

$50 \%$ patients were in young sexually active males. Testes were involved in 50\% cases. Most common sonographic feature was hypoechogenicity of the testes (37.5\% cases). Horstman WC et al.[13] reported involvement of testes in $20 \%$ to $40 \%$ of cases. They also reported that epididymis was the commonest anatomical structure involved in acute inflammation with hypoechogenicity. Associated peritesticular fluid and spermatic cord thickening was seen in $62.5 \%$ and $31.3 \%$ cases. CD could demonstrate increased flow with increased PSV and reduced RI.

Two testicular abscesses and one epididymal abscess were seen as complex fluid collections with internal echogenic material and debris. Similar findings have been reported by Horstman WC et al.[13]

\section{Chronic Inflammation}

Eighteen cases of chronic inflammation of scrotal structures were included in the study. Majority of age group of 21 to 30 years noted.

Testes were involved in $27.7 \%$ cases as compared to $83.3 \%$ of epididymis. Epididymis enlargement was diffuse (27.5\%) with hypoechoic echotexture (33.3\%).

Involvement of spermatic cord was noted in $38.9 \%$ cases. Evidence of tuberculosis in lung was associated in five cases $(27.7 \%)$. Epididymal calcification was noted in $5.5 \%)$ cases. Strikingly similar observations were noted by Kim et al. [14]

On CD, $22.2 \%$ of patients with chronic inflammation showed increased vascular signals; $5.5 \%$ testes and $5.55 \%$ of epididymitis (Normal on gray scale) showed increased vascularity on $\mathrm{CD}$ and were considered abnormal.

Thus, undiagnosed cases of orchitis and epididymis (One each) were detected, which were normal on gray scale sonography which was detected on CD. Increased sensitivity and specificity of $\mathrm{CD}$ to assess scrotal inflammation has been asserted by Barton JW.[15]

\section{Testicular Torsion}

Two cases of acute and one case of chronic testicular torsion were included in our study with all was under 20 years. Tumeh et al.[16] described torsion to occur commonly between the ages of 12 to 18 years. Features indistinguishable to those of torsion were noted in five cases of acute inflammation on gray scale sonography alone. Bird et al.[17] also remarked same.

On sonography, the commonest pattern was enlarged testes $(66.6 \%)$ with heterogeneous echopattern as most common pattern (66.6\%). Bird et al.[17] found similar findings in testicular torsion.

Changes in peritesticular tissue were also noted. The epididymis was enlarged in two cases (66.6\%) with hypoechoic echopattern in one case (33.3\%). In a single case of chronic torsion, the epididymis was enlarged and heterogeneous. Tumeh et al.[16] noted similar features in their series. In one case of testicular torsion, spiral twist of spermatic cord was noted. Baud et al.[18] described it to be a reliable sign of testicular torsion. With $\mathrm{CD}$, blood flow in symptomatic testes was absent in all three cases (100\%). However, CD could demonstrate flow signals on asymptomatic side only in two post-pubertal testes (66.6\%). No colour signal was identified on the asymptomatic side in a child aged four years with torsion.

In two patients, spectral analysis revealed decrease in RI with dampened flow, while in one patient the waveform was nearly venous. Baud et al.[18] described similar waveforms in their studies. 


\section{Testicular Trauma}

In the present study, four cases of testicular trauma were diagnosed. Sonography demonstrated hyperechoic echopattern in $50 \%$ cases. Increased size of testes was observed in two patients (50\%). Discrete fracture could be identified in one patient (25\%). Jeffrey et al.[19] noted similar findings.

Echogenic fluid suggestive of haematocele was noted in three patients (75\%). Jeffrey et al.[19] noted presence of haematocele in $83 \%$ cases in their series.

On $\mathrm{CD}$, no vascular signal was identified in one case $(25 \%)$ of blunt testicular trauma. In remaining three cases, normal intratesticular flow was seen.

\section{Testicular Atrophy}

$5 \%$ patients were showing testicular atrophy. The testes were noted to be hypoechoic in $33.3 \%$ and heterogeneous in $66.6 \%$ cases. The epididymis in all cases was small in size. Similar findings were found by Cross et al.[20]

\section{Varicoceles}

They comprised $15 \%$ of total number of cases comparable to $10 \%$ to $15 \%$ cases by Berger et al.[21]

They were seen more commonly on left side, as in our study also found by McClure et al.[22] All cases demonstrated accentuation on Valsalva manoeuvre and on erect posture. $40 \%$ cases were diagnosed on colour Doppler, which were undiagnosed by clinical examination suggesting colour Doppler more sensitive.

Greenberg et al.[23] found reflux in all cases, clinical varicocele as in our study. No significant difference in PSV in relation to presence or absence of varicocele and the degree of reflux was noted.

\section{Malpositioned Testes}

The incidence of cryptorchidism was $4 \%$ in our series. Its most common position was in inguinal canal, $50 \%$ cases also noted by Kleinteich et al.[24]

On sonography, $75 \%$ were homogeneous and hypoechoic in echotexture. Sizes of $50 \%$ testes were smaller than their contralateral counterpart. Torsion of undescended testes were noted in one case also noted by Nguyen and Hricak.[25]

\section{Testicular Cysts}

Hamm et al.[26] had an incidence of $4 \%$ of testicular cysts, while in our study it is $3 \%$. In all cases they were seen as well circumscribed, anechoic lesions with thin smooth walls and posterior acoustic enhancement. Malignant cysts were usually multilocular with shaggy, thick, poorly marginated walls and surrounded by neoplastic parenchyma with tumour vascularity. Horstman WG.[11] stressed on similar features to differentiate these two conditions. A case of tunica albuginea cyst was seen.

\section{Epididymal Cysts and Spermatoceles}

$7 \%$ cases of spermatocele and $11 \%$ cases of epididymal cysts were identified and confirmed on aspiration.

While the cyst contents were echogenic in $85.7 \%$ cases of spermatocele, it was anechoic in $100 \%$ cases of epididymal cysts. Septation were noted in $57.1 \%$ cases of spermatocele and in $9 \%$ cases of epididymal cyst. Doherty et al.[27] noted similar findings. On CD, blood flow in septae was seen in $28.5 \%$ cases of spermatocele and $9 \%$ cases of epididymal cyst.

\section{Scrotal Hernias}

Omentocele was $3 \%$ cases, while enterocele in $4 \%$ cases. Thus, an incidence of $7 \%$ was noted. An incidence of $7.6 \%$ was noted by Subramanyam BR et al.[28] in their study. In our study, sonography revealed a highly echogenic mass separated from the testes in omental hernia and anechoic mass in inguinoscrotal region of in cases of enterocele. Subramanyam BR et al.[28] noted similar findings.

On CD, vascular signals were demonstrated within the bowel wall and within the omentum.

One postoperative case of herniorrhaphy was studied, which had multiseptated collections in the spermatic cord. Another patient had thickened spermatic cord with no traceable vascular signals in the cord or ipsilateral testes. The testes had atrophied in this case.

\section{Testicular Microlithiasis}

In our study testicular microlithiasis have incidence of $6 \%$ with $4 \%$ cases had bilateral testicular microlithiasis with associated teratocarcinoma on $1 \%$ case. Doherty et al.[29] described similar findings with a reported incidence of $0.6 \%$.

\section{Scrotal Wall Oedema}

Scrotal wall oedema was found in two patients, one due to heart failure and second due to filariasis. Scrotal wall thickened with multiple layers like onion peel. Thickening of penile skin was also noted in both cases. Grainger et al.[30] described similar findings.

\section{ACKNOWLEDGEMENT}

We acknowledge Dr. R. K. Mathur for guiding us in every step of research work. We also acknowledge Dr. Vijay Bahadur Singh, Dr. Anuja Patil, Dr. Mukesh Patidar, Dr. Parul Gupta, Dr. Bhagyashree Patil, Dr. Viral Shah and Dr. Manohar Singh Rathore for her assistance with the radiologic findings and $\mathrm{Mr}$. Indal Singh for his assistance in statistics work. Mr. Shri Jalim Singh, Smt. Pushpa Singh, Smt. Pooja Singh, Mr. Rahul Shrivastava and Mr. Ravikant Gupta for mental support and technical help during study.

\section{REFERENCES}

1. Miskin M, Bains J. B-mode ultrasonic examination of the testes. J Clin Ultrasoun 1974;2:307-311.

2. Langer JE. Ultrasound of scrotum. Seminars in Roentgenology 1993;28:5-18.

3. Gutman H, Golimbu M, Subramanyam BR. Diagnostic ultrasound of scrotum. Urology 1986;27:72-75.

4. Stewart R, CaroII BA. The scrotum: in diagnostic ultrasound. St. Louis. Rumack CM, Wilson SR, Charboneau JW. Elsevier Mosby; 1991;2nd edition.

5. Chung SE, Frush DR, Fordham LA. Sonographic appearances of extratesticular fluid and fluid containing scrotal masses in infants and children due to diagnosis. AJR 1999;173:741-745.

6. Fowler RC, Chennells PM, Ewing R. Scrotal ultrasonography: a clinical evaluation. $\mathrm{Br} \mathrm{J}$ Radiol 1987;60:649-654 
7. Arger PH, Mulhern CB Jr, Coleman BG, et al. Prospective analysis of the value of scrotal ultrasound. Radiology 1981;148:209-211.

8. Nachtsheim DA, Scheible FW, Gosinki B. Ultrasonography of testes tumours. J Urol 1983;129:978-981.

9. Grantham JG, Charboneau JW, James EM, et al. Testicular neoplasm: 29 tumours studied by high resolution ultrasound. Radiology 1985;157:775-780.

10. Berger A, Brabrand K. Testicular microlithiasis-a possibility premalignent condition. Acta Radiologica 1998;39:583-586.

11. Horstman WG, Melson GL, Middleton WD, et al. Testicular tumours: findings with colour doppler US. Radiology 1992;185:733-737.

12. Mostofi FK. Testicular tumours: epidemiologic, etiologic and pathologic features. Cancer 1973;32:1186-1201.

13. Horstman WC, Middleton WD, Melson CL. Scrotal inflammatory disease: colour doppler ultrasound findings. Radiology 1991;179:55-59.

14. Kim HS, Yang DM, Yoon $\mathrm{MH}$, et al. Comparison of tuberculous and pyogenic epididymal abscesses: clinical, gray-scale sonographic, and colour doppler sonographic features. AJR Am J Roentgenol 2001;177(5):1131-5.

15. Barton JW, Brown JM, Hammers LW, et al. Quantitative doppler assessment of acute scrotal inflammation. Radiology 1995;197(2):427-31.

16. Tumeh SS, Benson CB, Richie JP. Acute diseases of the scrotum. Semin US CT MR 1991;12:115-130.

17. Bird K, Rosenfield AT, Taylor KJW. Ultrasonography in testicular torsion. Radiology 1983;7:527-534.

18. Baud RO, Kennelly MJ, Adler RS, et al. Nonpulsatile arterial waveforms experimental study during graded testicular torsion in an animal model. Radiology 1994;193:335-336.
19. Jeffrey RB, Laing $\mathrm{FC}$, Hricak $\mathrm{H}$, et al. Sonography of testicular trauma. AJR 1983;141:993-995.

20. Cross JJL, Berman LH, Elliott PG, et al. Scrotal trauma a cause of testicular atrophy. Clinical Radiology 1999;54:317-320.

21. Berger OG. Varicocele in adolescence. Clin Pediatr 1980;19:810-11.

22. Mc Clure R, Hricak H. Scrotal ultrasound in the infertile man: detection of subclinical unilateral and bilateral varicocele. J Urol 1986;135:711-715.

23. Greenberg SH, Lipshultz LI, Wein AJ. A preliminary report on "subclinicalvaricocele": diagnosis by doppler ultrasonic stethoscope. J Reprod Med 1979;22:77-80.

24. Kleinteich B, Popp W, Grahl KO. Congenital testicular dystopias and concomitant abnormalities. Kinderarztl Prax 1979;47(7):357-62.

25. Nguyen HT, Hricak H. Cryptorchidism: strategies in detection. European Radiology 1999;9:336-343.

26. Hamm B, Foboe F, Loy V. Testicular cysts: differentiation with ultrasound and clinical findings. Radiology 1988;168:19-23.

27. Doherty FJ. Ultrasound of the nonacute scrotum. Semin Ultrasound CT MR 1991;12:131-156.

28. Subramanyam BR, Balthazar EJ, Raghavendra BN, et al. Sonographic diagnosis of scrotal hernia. AJR 1982;139:535-538.

29. Doherty FJ, Mullins IL, Sant GR, et at. Testicular microlithiasis: a unique sonographic appearance. J U Med 1987;6:389-392.

30. Grainger AS, Hide IG, Elliot ST. The ultrasound appearance of scrotal odema. Eur J UItrasound 1998;8:33-37. 